\section{EL DERECHO A LA EDUCACIÓN EN COLOMBIA 1830-1853. LA HISTORIA EN EL PRESENTE ${ }^{*}$}

\section{Lina Marcela Escobar Martínez ${ }^{* *}$ Universidad Militar Nueva Granada}

Fecha de recepción: 22 de abril de 2009

Fecha de aceptación: 15 de mayo de 2009

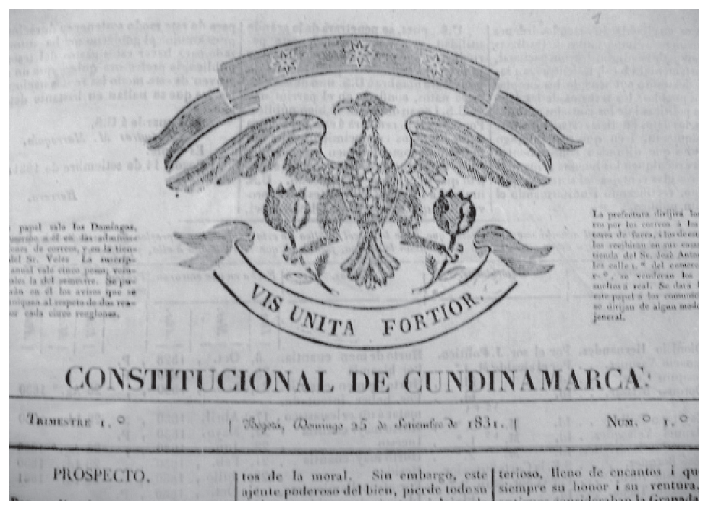

\section{Resumen}

La educación ha sido siempre una preocupación compartida por los sectores públicos, privados y por la Iglesia como factor real de poder. La importancia de la educación está dada entre otros muchos factores por la capacidad de difusión de ideas y la posibilidad de construcción de otras nuevas.

El derecho se ha ocupado de reconstruir las consagraciones constitucionales del derecho a la educación, así como su reglamentación y legalización en los diferentes periodos históricos, con lo cual el análisis ha estado focalizado en la

\footnotetext{
Articulo resultado de la investigación "Bicentenario constitucional colombiano 1810-2010", realizada entre las Universidades de Medellín, Manizales, Libre de Colombia y Militar Nueva Granada.

** Abogada Universidad Pontificia Bolivariana. Magister en Derecho Público de la Universidad Externado de Colombia. Magister en Derecho Constitucional y Parlamentario de la Universidad Complutense de Madrid. Doctora en Derecho de la Universidad de País Vasco. Docente investigadora de la Universidad Militar Nueva Granada. Carrera 11 No. 101-80, Bloque B - Piso 1. Teléfono: 6343262. Correo electrónico: lina.escobar@ unimilitar.edu.co
}

normatividad, quedándose en un enfoque netamente positivista que si bien es cierto, es el centro del que hacer jurídico, también lo es que la investigación que hoy nos ocupa parte del positivismo y llega hasta la dogmática, pues siendo este un trabajo que busca conmemorar el bicentenario constitucional es necesario aportarle a la reconstrucción y construcción de la historia un análisis incluyente, en donde los hechos, los contextos y los principios son utilizados como lentes para la reflexión sobre las normatividades existentes en el periodo señalado.

Este artículo está dedicado a reconstruir la historia del periodo comprendido entre $1830 \mathrm{y}$ 1853 y toma como fuente única el periódico "E1 Constitucional de Cundinamarca", con ello se pretende reseñar las controversias en materia educativa en este departamento, ya que la investigación busca realizar análisis comparativos acerca de la evolución y desarrollo de los derechos en cada una de las regiones del país, para luego confrontarlas con las declaraciones nacionales y su posterior regulación general.

El artículo se divide en dos partes, la primera dedicada al estudio de la educación en Colombia, su importancia y contenidos, se divide en tres partes la importancia de la educación según los líderes de Cundinamarca de la época; la sana moral y otras asignaturas en la educación colombiana; y las características de la instrucción primaria; la segunda parte está dedicada al estudio de la educación desde su alcance y regulación, y se divide en tres partes, la enseñanza de la economía política, las casas de educación y el Código de instrucción pública. Se aclara que todas las citas no tienen un autor, puesto que en el periódico El Constitucional no aparecen referenciados los autores de los artículos, lo que si deja claro es la edición y la fecha de publicación del artículo. Adicionalmente, se anota que este periódico es de circulación quincenal, y que el cuerpo de sus redactores son políticos conservadores con formación en la doctrina cristiana.

\section{Palabras clave}

Educación, casas de educación, instrucción pública. 


\section{EDUCATION RIGHTS IN COLOMBIA 1830-1853. THEHISTORYINTHEPRESENT}

\begin{abstract}
Education has always been a concern shared by the public, private and by the Church as a real power. The importance of education is given by many factors including the ability to disseminate ideas and the possibility of building new ones.
\end{abstract}

The law has worked to rebuild the consecrations of the constitutional right to education and its legalization and regulation in different historical periods, so the analysis has been focused on the rules, staying in a purely positivist approach is that while Indeed, it is the center of the legal to do, so that research is today part of positivism and goes to the dogma, because this being a work that seeks to commemorate the bicentennial of the Constitution is necessary to bring the reconstruction and construction of the an inclusive history analysis, where the facts, context and principles are used as lenses for thinking about existing regulations in the period indicated.

This article is dedicated to reconstructing the history of the period between 1830 and 1853 as a single source and takes the newspaper the Constitutional Cundinamarca This is intended to outline the controversies in education in this department, the research aims to conduct comparative analysis on the evolution and development of rights in every region of the country, then compare with the national statements and subsequent regulation generally.

The article is divided into two parts, one devoted to the study of education in Colombia, its significance and content, is divided into three parts, the importance of education as the leaders of the era of Cundinamarca, the moral and healthy subjects Colombian education and the characteristics of the primary, the second part is devoted to the study of education from the scope and regulation, and is divided into three parts, the teaching of political economy, home education and the Code of public education. It is clarified that all appointments are not an au- thor, since in the newspaper The Constitutional referenced are not the authors of the articles, it is clear that the editing and publication of the article. Additionally, it notes that this movement is bi-weekly newspaper, and the editors are trained in Christian doctrine.

\section{Keywords}

Education, home education, public education.

\section{EL PAPEL DE LA EDUCACIÓN EN LA TRANSFORMACIÓN DE LA SOCIEDAD COLOMBIANA ${ }^{1}$}

Una de las discusiones que se observan frecuentemente en los periódicos de la época, se centra en la importancia de la educación para el pueblo colombiano y en las ventajas que resultarían al generalizar la instrucción, llegando incluso a proponerse que debería extenderse hasta los indigentes, pues evitaría sus crímenes y descarríos $^{2}$. La educación como medio de evolución de la sociedad, permitiría al pobre entrar a la sociedad y evitaría que el rico por su ignorancia tarde o temprano se arruinara y se viera despreciado por una sociedad que ya habría alcanzado un grado de educación tal, en donde el dinero no sería el factor determinante para tener un liderazgo en la sociedad.

Por otra parte, la educación era considerada el único medio de liberación real de la sociedad colombiana frente a la tiranía española, pues de nada servía una sociedad formalmente libre cuando sus ideales y sus proyecciones aun tenían grandes influencias colonialistas que impedían el surgimiento de una identidad cultural propia en donde se reconocieran las diferencias y se creciera en ellas.

Ser educado se convertía entonces, para la época en un asunto de honor y en una posibilidad de ascender socialmente sin utilizar la violencia, pues el joven que se dedicaba al estudio, no

El constitucional. Trimestre 2, domingo 1 de enero de 1832.

2 El constitucional. Trimestre 4, domingo 19 de agosto de 1832 . 
lo hacía por el deseo de salir de un trabajo árido y penoso, ni por cumplir solamente con la obligación que le imponían sus padres o curadores, sino por el interés de ilustrar su entendimiento y cultivar su espíritu.

Es de resaltar, que muchos cuestionamientos se orientaban a la jerga escolástica que se utilizaba en la educación de la época de la colonia, llegándose incluso a afirmar que la desaparición de dicho lenguaje eliminaba el temor y ampliaba la fuente del saber. Con lo cual, encontramos que desde entonces la claridad en el lenguaje y los métodos de enseñanza han sido una preocupación en nuestro medio, pues no bastaba con saber, sino que existía un reclamo permanente por conocer, pues se decía que sólo quien conocía podía transmitir y de esta forma el conocimiento se transformaba en sabiduría, y la educación en un medio de progreso para la sociedad.

Al respecto encontramos afirmaciones como estas:

Parece, pues, que una era de prosperidad y de gloria literaria, empieza en la Nueva Granada con un gobierno protector de las luces, con instrucciones liberales, y con la más eficaz cooperación, la juventud granadina estudia con aprovechamiento en los colegios, de donde han de salir algún día hombres que den honor a la nación en todas las profesiones, que dirijan sus destinos, y la eleven al mayor grado de felicidad posible. Bajo estos auspicios empieza la existencia política del estado, que va a recoger el fruto de la pasada experiencia, y de los esfuerzos de sus magis$\operatorname{trados}^{3}$ (negrillas fuera de texto).

La educación y el pueblo educado vislumbran la existencia política del Estado, no nos queda más que preguntarnos hoy en día, si hemos logrado esos ideales de 1831 o si aun continuamos en la construcción política con resultados no muy satisfactorios.

El constitucional. Trimestre 4, domingo 19 de agosto de 1832 .

\section{LA SANA MORAL Y OTRAS ASIGNATURAS EN LA EDUCACIÓN COLOMBIANA}

En los periódicos de la época, se encuentra un marcado énfasis en la importancia de la sana moral en la educación colombiana, y la aclaración de que ésta nunca ha estado en pugna con la verdadera ilustración, razón por la cual, los jóvenes deberían adquirir conocimientos útiles en todas las ramas del saber humano, y hacían la aclaración de que dichos conocimientos científicos deberían velar por la conservación de la pureza de su corazón y de sus costumbres.

En consecuencia, lecciones de virtud y urbanidad, la cultura de modales, la delicadeza del trato social, tan descuidadas en otro tiempo (así como hoy en día) hacían parte de la educación escolar. La descortés pedantería era considerada hija de la ignorancia y del mal ejemplo, pues una persona educada, tenía en su corazón los más nobles sentimientos que le impedirían discriminar al otro por sus condiciones y en su lugar se preocuparía por enseñarle lo que él había logrado conocer a través de su instrucción.

Los directores de la educación no podían entonces limitarse a la enseñanza de las ciencias; sino que debían proporcionar a sus alumnos recreaciones agradables en el aprendizaje de las bellas artes. Se citan dos ejemplos, el primero: un cuadro estadístico del régimen interior del colegio del Rosario, en donde muestra el establecimiento en aquel colegio de las cátedras de la lengua francesa e inglesa, y la enseñanza de música y dibujo; el segundo, son las enseñanzas de los Jesuitas en el colegio de San Bartolomé.

Las asignaturas dictadas en la época eran las siguientes: Gramática latina, francesa, aritmética, algebra, geometría, geometría elemental, trigonometría rectilínea y geometría práctica, fundamentos de la religión, moral, cosmografía, geografía en sus tres ramos, gramática francesa, temas y locución inglesa, gramática inglesa, historia sagrada, religión, ideología, mecánica, estática, dinámica, hidrostática, hidrodinámi- 
ca, física general, calórico, evaporación, frío artificial, luz, electricidad, galvanismo, magnetismo, electricidad dinámica, agua, humedad, aire, combustión, sonido, meteorología, vientos, vapores y principios de política constitucional.

Los exámenes eran orales y públicos, se examinaba cada asignatura por separado y cualquier persona podía asistir a las sustentaciones. Se hacía énfasis en la claridad y en la necesidad de que se dictarán leyes en donde se especificara que todas las instituciones deberían brindar instrucción en cada una de estas asignaturas pues no se podrían generar desigualdades en la educación y por ello también se promovía que los colegios deberían ser mixtos.

Con el paso del tiempo se hacían frecuentes las críticas con relación a los contenidos y las asignaturas mismas que cada institución ofrecía, pues se cuestionaba el hecho de darle más importancia a la instrucción en contenidos que a una formación integral de los niños y jóvenes en donde la moral y el comportamiento justo fuera el norte de la educación, pues ese era el fin propuesto desde el inicio al masificar la educación, que podría sintetizarse en la construcción de sociedad-nación mediante la instrucción. Prueba de ello es el siguiente párrafo del periódico El Constitucional de Cundinamarca:

"Les falta a los niños de nuestras escuelas la educación moral, la única que puede formar hombres y ciudadanos, y esta educación les falta porque sus mismos maestros no la han recibido. Nosotros damos un valor solamente secundario a la instrucción puramente material, que enseña al pueblo a leer, escribir y contar: en ella no hay más que medios de educación, que vendrán a ser buenos o malos según la dirección que se les de. Son luces que pueden servir de antorchas para ilustrar a los que la poseen, o de teas para difundir a lo lejos el incendio. El verdadero objeto, hablemos con más exactitud, el único objeto de toda instrucción efectiva, es procurar una perfección moral: ilustrar al pueblo es poca cosa, cuando no se cuida de moralizarle al mismo tiempo"4 (negrilla fuera de texto).

La enseñanza de la moral y sus principios se presumía asegurada en los pensum de las instituciones privadas que generalmente eran regentadas por comunidades religiosas, lo cual no era totalmente cierto, pues se confundía en algunos casos la filosofía y la moral. La preocupación principal se centraba en la enseñanza de la moral en las instituciones públicas, pero haciendo énfasis en que debería ser obligatoria en todas las instituciones de enseñanza sin importar su carácter público o privado, pues al no incluirse se estaba generando una desigualdad en la educación de la población colombiana y no se estaría cumpliendo con los fines sociales de la educación antes mencionados.

"No es solamente para los niños del pueblo para los que pedimos una enseñanza pública de la moral: nosotros la consideramos como absolutamente necesaria para los niños y los jóvenes de todas clases. La enseñanza filosófica, aunque fecunda en lecciones grandes y útiles, no basta, es necesario además, que hombres virtuosos sabios y elocuentes, se levanten entre nosotros para enseñar la moral más pura. Este es uno de los más poderosos medios de clamar, de parar, y traer a la orden de la razón y a la moderación las pasiones políticas que amenazan invadirlo todo y alterar hasta los principios de la moral, aún en los corazones honestos y generosos. Nosotros iremos más lejos y querríamos que el gobierno pensase también en establecer gradualmente una enseñanza de la moral para todo el pueblo"s.

La enseñanza de la moral tenia además una connotación política, pues se concebía que un pueblo no educado no podría llegar a cumplir con su libertad democrática dentro de un contexto político, por ello se hacía énfasis en que tener cono-

4 El constitucional. Trimestre 1, domingo 18 de diciembre de 1831 .

5 El constitucional. Trimestre 1, domingo 25 de diciembre de 1831. 
cimientos no aseguraba bajo ninguna perspectiva la construcción de sociedad, pues al momento de elegir la población se dejaría llevar por sus pasiones y no por elementos de juicio racionales.

"Esta falta de la más necesaria de las enseñanzas es un funesto vacío en nuestro Estado Social: es absolutamente necesario llenarle si queremos formar un pueblo que sea digno y capaz de la libertad"6.

Vale la pena resaltar que en muchos escritos colombianos de los años veinte y treinta a los que se recurrieron para hacer este artículo de investigación, se utiliza la denominación de Estado Social, cuando en realidad para la época el modelo de Estado era el de derecho. En el caso de la educación se cuestionaba el hecho de si era el gobierno el encargado de velar por los contenidos que se impartían en las instituciones de enseñanza, llegándose a preguntar, sí precisamente dicha intervención no atentaría contra los principios del Estado Social.

¿Será el gobierno quien podrá llenar esta elevada e importante misión? Si él la emprendiera ¿no saldría de los límites que le están impuestos por los mismos principios del estado social? ¿No encontraría dificultades mayores y más insuperables que los simples particulares que se asocien para este fin? ${ }^{7}$

Entender estos cuestionamientos a luz de la Constitución de 1991 y de los postulados del Estado Social de Derecho que hoy conocemos, no resulta para nada novedoso o problemático, puesto que la libertad de enseñanza, los derechos de las personas jurídicas, la autonomía educativa en sus diferentes niveles de instrucción, etc., son temas que han sido ampliamente desarrollados en la jurisprudencia de la Corte Constitucional colombiana. Lo que sí es un misterio es cuales serian los principios del Esta-

$6 \quad$ El constitucional. Trimestre 6 domingo 10 febrero 1833.

$7 \quad$ El constitucional. Trimestre 7 domingo 23 junio de 1833. do Social a los que se referían con tanta seguridad los doctrinantes colombianos de los años veinte y treinta.

Una hipótesis que he construido mediante un método inductivo uniendo argumentos de diferentes textos, es que lo que existía para el momento era una separación clara entre los asuntos públicos y los asuntos privados, en donde el gobierno aparecía como un agente regulador de lo público pero en ningún caso interfiriendo directamente en los asuntos privados, por eso cuando se decía que la educación debería tener como norte la moral, se reprochaba el hecho de que a través de dicha enseñanza a lo que se podría llegar es a una secularización de la educación con todas las connotaciones que ello acarrea en una sociedad diversa en donde los principios y valores de la sociedad no se reducen a los principios cristianos, y en donde en el fondo lo que seguía vigente era la lucha entre una ideología conservadora y otra liberal.

"Los principios de la fe son el único fundamento de las máximas de conducta. Para ser virtuoso es necesario aceptar previamente las doctrinas que prescriben y sancionan la virtud. Para aprender a llenar sus deberes respecto de si mismo y de los demás es preciso aprender antes de todo a llenar sus deberes respecto de Dios.

No hay absolutamente enseñanza moral sin religión, y ninguna otra religión posible el día de hoy sino el cristianismo. Más no es el gobierno el que acertará a volver a encender la antorcha del evangelio entre nosotros: esta obra pertenece a aquellos que creen, y que desean creer en las verdades de la revelación, ella pertenece a la imprenta que hasta hoy no ha sabido comprender cuanto podría hacer para mejorar la moral de la nación".

\section{LA INSTRUCCIÓN PRIMARIA}

Esta instrucción era una preocupación nacional común, por ello se encuentra que en el Cauca, 
el periódico número 54 del "Constitucional del Cauca", correspondiente al 10 de agosto de 1833 bajo el título de asociación importante, se apoyaba lo escrito en el periódico "El Corresponsal", publicado también en Popayán, ambos escritos proponen la formación de una sociedad para fomentar la instrucción primaria. $\mathrm{Al}$ respecto:

"Para reformar completamente la instrucción primaria, y fundarla según los adelantamientos que han hecho los sistemas de enseñanza mutua y enseñanza simultánea, y difundirla por toda la nación, es preciso promover una reunión, de hombres celosos por el bien público, que se consagren a secundar los esfuerzos del gobierno, y que contribuyan anualmente con una suma aunque pequeña para este objeto: que, con este fin, debería formarse una sociedad que se ocupase especialmente de organizar y propagar este sistema en todas las provincias y hasta en todos los cantones, adelantándolo y perfeccionándolo en las ciudades de más recursos" 8 .

La educación se concebía entonces como un deber no sólo del Estado sino también de los particulares y de la sociedad en general, ya que la educación debería ser general. Para lograr este objetivo se creó una comisión encargada de llevar a efecto aquellas medidas que se creyesen convenientes, de velar en el empleo de los fondos, de procurar a los Gobernadores, a los Jefes Políticos y a los individuos que quisieran establecer escuelas, las nociones que necesitasen, los maestros formados según el nuevo sistema, los impresos de que se hiciese uso para enseñar a los niños a leer, escribir, calcular y demás enseñanzas. ${ }^{9}$

Con estas medidas que aún hoy se utilizan, lo que se pretendía era crear una estandarización mínima de la educación nacional, en donde

El constitucional. Trimestre 10 domingo 30 marzo 1834. El constitucional. Trimestre 9 domingo 29 de diciembre 1834. si bien se respetaba la libertad de cátedra y la ideología de las instituciones, se cumpliera con unos requisitos mínimos, de forma tal que el nivel de educación establecido como mínimo se garantizara por todas las instituciones; hoy en día podría equipararse a los requisitos establecidos por el CNA (Consejo Nacional de Acreditación) en lo relativo a los registros calificados de los programas independientemente del nivel de educación (primero, segundo, tercero).

La instrucción primaria ocupaba un papel protagónico en Colombia durante los años treinta, llegándose a equiparar a la actividad legislativa, incluso se afirmaba que existía una interdependencia entre ambas, con lo cual, la libertad ideológica en las instituciones queda ampliamente cuestionada y es evidenciada con la expulsión de la Comunidad Jesuita en varias ocasiones del territorio colombiano.

La educación desarrollada dentro de ciertos parámetros era considerada como un mecanismo de promoción del concepto de ciudadanía, pues estaba siempre presente la necesidad de instruir al pueblo acerca de sus derechos pero también de sus deberes, haciéndose incluso más énfasis en sus deberes, pues la limitación de los derechos individuales o su ejercicio debido, garantizaría el no irrespeto de los derechos de las demás personas, generando con ello una conciencia ciudadana. Al respecto encontramos en el periódico el Constitucional de Cundinamarca lo siguiente:

"Si la educación, como dice un hombre célebre de nuestros días, es una institución $\tan$ necesaria a los Estados como la legislación; si ella debe ser relativa a la forma de gobierno; y si las costumbres llevan la divisa de las leyes, se convencerá de la necesidad de procurar todos los medios de fomentarla de una manera sólida y durable. Las asociaciones, prestando una poderosa cooperación a la autoridad, contribuyen a formar los niños en todos los hábitos que pueden concurrir a su dicha futura, y acostumbrarlos a una regla fija que los dirija en 
todas sus acciones: en fin, a enseñarle sus deberes, como hombres, y como ciudadanos, inculcándoles los primeros elementos de la moral. Los padres de familia evitarán que sus hijos reciban una instrucción arbitraria sin dirección y sin objeto, que haría su destino incierto, y su conducta dudosa" ${ }^{10}$.

En definitiva encontramos que en la práctica, la administración de la educación estaba en todas las provincias a cargo del Gobernador, quien protegía y promovía la creación de las asociaciones. Desde el plano normativo, el artículo segundo de la ley del 18 de marzo de 1826, establecía que la dirección general de estudios tenia entre otras atribuciones, la de formar reglamentos para el arreglo literario y el gobierno económico para las escuelas, y promover todo lo que mire al fomento de la educación moral y política.

\section{LA ENSEÑANZA DE LA ECONOMÍA POLÍTICA $^{11}$}

El Colegio San Bartolomé, regentado desde su inicio hasta la actualidad por la Comunidad Jesuita, fue uno de los pioneros en la enseñanza de la economía política, asignatura bastante cuestionada en la época de los años veinte y los treinta, pues si para algunos constituía una base importantísima de la sociedad y era necesario que toda persona desde sus primeros años de enseñanza fuera teniendo conocimiento de la economía política, concebida como un conjunto de postulados universales ${ }^{12}$, para otros era una amenaza su instrucción pues algunas personas podrían pretender traer al contexto colombiano los postulados de la economía po-

10 El constitucional. Trimestre 10 domingo 30 marzo 1834.

11 El constitucional. Trimestre 6 domingo 24 febrero de 1833.

12 De aquí podríamos sacar alguna ventaja para probar que los principios de la economía política bien aplicados, son útiles y necesarios bajo todas latitudes, porque la verdad es una en cualquier grado del meridiano. El constitucional. Trimestre 6 domingo 24 febrero de 1833. lítica que habían sido generados en latitudes diferentes a la nuestra y con factores políticos, jurídicos y económicos distintos que harían que la aplicación de dichas políticas o postulados en nuestro medio fueran ineficaces o ineficientes. $\mathrm{Al}$ respecto:

"La doctrina parece cierta, pero no estamos en el caso de adoptarla. No todo lo que debe hacerse, se puede. No es tiempo aún. Una cosa es escribir y otra obrar. No es lo mismo la teoría que la práctica. La oposición entre lo recto y lo conveniente, entre lo teórico y lo práctico es una antigua enfermedad de la flaqueza humana. El verdadero sentidoo consiste en obrar cuando se está convencido de la rectitud de la operación, y si una teoría se haya bien demostrada es seguro que la práctica no puede fallar, porque esta ha servido ya para establecer aquella, en una ciencia que es experimental como la economía política"13.

\section{LAS CASAS DE EDUCACION ${ }^{14}$}

Estas casas eran instituciones privadas en donde se impartía la educación a un sector privilegiado económicamente de la población colombiana, no necesariamente tenían que ser alumnos nacidos en la provincia de Cundinamarca, podían provenir de cualquier parte del país, pero si debían pertenecer a la clase mas adinerada.

Las casas de educación tenían reglamentos internos de funcionamiento en donde se consagraban las obligaciones recíprocas que contraían tanto los padres de familia, como el director de la misma casa.

La conformación de estas casas era bastante particular, pues se anunciaba en las parroquias su creación, una vez concurrían los padres de familia interesados se realizaba una reunión en donde éstos en unión con el director de la

13 El constitucional. Trimestre 10 domingo 30 marzo 1834

14 El constitucional. Trimestre 12 domingo 14 septiembre 1834 . 
escuela discutían las bases de formación propuestas por la institución y determinaban si los acuerdos logrados debían ser elevados a una escritura pública o no, según lo que se crea conveniente para la seguridad de sus mutuos intereses, o variar lo que se juzgaba contrario a los principios de rigurosa justicia.

El número máximo de alumnos era cuarenta, ingresaban desde los siete años hasta los catorce años, la pensión era de 16 pesos mensuales y se pagaban por trimestre adelantado, los estudios tenían una duración de cuatro años si el joven ya sabía leer y escribir, de lo contrario tenía una duración de cinco años.

Las asignaturas normalmente eran: las gramáticas castellana y latina; y los indispensables rudimentos del francés; las materias del curso de filosofía debían estar conforme a lo que señala la ley de la materia; y la escritura con arreglo a lo dispuesto por la dirección general de estudios sobre este particular y dibujo.

Cada año por el mes de junio se presentaban certámenes públicos de las materias del curso. Fuera de estos había uno privado, a la mitad de este periodo, por diciembre; en donde eran examinados los concursantes por sus mismos padres, o por las personas de su satisfacción que ellos nombraran.

Los alumnos no podían salir de la casa de pensión sino los domingos y días festivos, por la mañana desde las 8 hasta las 6 de la tarde, hora en la que debían regresar, pues ninguno podía pernoctar fuera, las vacaciones eran por espacio de un mes después de los exámenes y en la semana santa desde el domingo de ramos. Si un alumno tuviere que salir temporalmente por enfermedad y esta pasare de los 8 primeros días desde este término no pagaba pensión hasta que volviera. Es de aclarar, que los dos meses al año de vacaciones debían en todo caso ser pagados a la institución educativa.

El contrato de educación era bastante particular, pues para su terminación por parte del pa- dre debería seguirse un procedimiento que consistía en que el padre o acudiente que tratara de sacar de la casa de pensión a un alumno, debía manifestar antes la causa que tenia para ello; pero si este no la estimare legítima, la calificaba una junta de cinco individuos tomados de entre los mismos padres, nombrándose 2 por cada parte y el otro se sacaba a la suerte y oídas las partes, la junta decidía el negocio; pero si esta decisión fuere contraria a las pretensiones del padre; y a pesar de esto, las llevase a efecto pagaba inmediatamente por vía de indemnización el total de un trimestre, esta ultima parte no tenía lugar siempre que esté presente otro joven que sustituya al que ha salido con tal que reúna las circunstancias requeridas.

Cada alumno a su entrada a la casa de pensión debía llevar una cama, un paño de manos, cepillo de dientes y de zapatos, un peine, tijeras y un baúl mediano, llevaba también el papel para escribir y dibujar que el director creía necesario, y una caja de colores si estaba adelantado en el dibujo. Todos los miércoles y sábados desde las 5 hasta las 6 de la tarde recibían de sus casas con el correspondiente apunte, una muda de ropa limpia y devolvían la usada, también con apunte, los jueves y domingos desde las 7 hasta las 8 de la mañana, para cuyo efecto mandaban siempre un sirviente de cada casa.

\section{CÓDIGO DE INSTRUCCIÓN PÚBLICA ${ }^{15}$}

Cumpliendo con uno de sus deberes constitucionales y con el especial encargo que le izo la Convención Granadina por el Decreto del 27 de marzo del año de 1832 el Consejo de Estado se ha ocupó de la instrucción pública y redactó un proyecto de código que fue sometido a discusión en la Cámara de Representantes del Congreso Colombiano.

La Convención al realizar el encargo al Consejo de Estado, le pedía una resolución al problema de la libertad de enseñanza indicada por

5 El constitucional. Trimestre 7 domingo 23 junio de 1833. 
el decreto de la convención, combinada con las garantías a que la sociedad tiene derecho y el deber de exigir de aquellos a quienes ha de confiarse la educación las mejores calidades personales y académicas.

El proyecto estaba dividido en 8 títulos, sub divididos en capítulos. De la importancia vital o más bien de la necesidad de la instrucción pública y general para el buen orden bienestar y subsistencia de la sociedad, bajo un gobierno constitucional, se ha sacado por consecuencia en su título $1^{\circ}$ preliminar, el deber y el interés que esta tiene de proporcionar o facilitar, y extender los medios de instrucción: el derecho de exigir que todos contribuyan a las expensas de este servicio público, y los padres una vez que se les ofrezcan los medios de que sus hijos reciban la instrucción por lo menos elemental, hagan constar a la sociedad que la reciben: y por último la super vigilancia que la autoridad administrativa puede y debe ejercer sobre los establecimientos de instrucción pública y privada en que se encierra el porvenir de la sociedad.

El título segundo comprende el sistema de dirección e instrucción pública, distribuye por todo el Estado sus agentes y modifica su autoridad según la esfera de su acción. A su cabeza está una dirección general a la inmediación del supremo gobierno, supliendo la falta de un ministerio especial para los asuntos de educación.

La dirección general impartía las políticas y se recibían por parte de las subdirecciones en cada distrito universitario, ellas lo transmitían a las inspecciones de cada provincia y descendiendo de estas a las juntas cantonales, llegaba a las juntas parroquiales de instrucción pública. Coordinados a este fin, los deberes y funciones, la dependencia gradual y la constante comunicación de estos diversos agentes, trabajaban mediante una cooperación simultánea, y eficaz a favor de la instrucción pública.

Dos novedades para la época se dieron en este título: la reducción de la dirección, subdirecciones e inspecciones a un solo individuo y la asig- nación que se le hace de un sueldo. En cuanto a los gastos de la dirección en inspección e instrucción pública se observa en el proyecto de decreto complementario del código que se han distribuido entre los fondos públicos y los provinciales según que los agentes se han considerados como nacionales o locales.

En las Juntas Parroquiales terminaba la acción directiva de la acción pública. Ellas se denominaban parroquiales porque la esfera de su acción es llamada en la Constitución: Distrito Parroquial, y el Congreso, consideró tal vez suficiente esta razón, así como considero suficiente el Concejo, para que a los Concejos que se establezcan en los distritos parroquiales se les de el nombre de Consejos Parroquiales y no comunales.

Los establecimientos de instrucción pública y sus auxiliares ocuparon una buena parte del proyecto en su título $3^{\circ}$ que trata de las universidades, colegios, seminarios, colegios de niñas, escuelas, sociedades de varias clases, bibliotecas, museos y observatorios. El Concejo creyó que además de la educación moral e intelectual, la juventud podía empezar a recibir en los colegios y aún en las escuelas la educación política o civil; y con este objeto introdujo en sus reglamentos el sistema de elecciones, un ensayo del jurado, y una participación de los alumnos en el régimen de los establecimientos: pero en todo caso consultando antes si las circunstancias particulares de cada localidad, prometían el buen resultado de estas disposiciones.

Respecto de los seminarios, se consideró su dependencia de la autoridad del prelado diocesano con la inspección de la autoridad pública. Los colegios de niñas, buscan asegurar mediante la enseñanza de oficios la seguridad de la vida futura de las mujeres. Tratando de las escuelas, el proyecto entra y se extiende en varios pormenores respecto de la instrucción primaria. La grande importancia, o más bien la urgente necesidad de su pronto y general establecimiento, y de su mejor arreglo hicieron indispensable que la ley contuviese disposiciones, y diese ba- 
ses para uno y otro, haciendo énfasis en que la instrucción debía ir hermanada con la religión, la virtud y el patriotismo.

El título $4^{\circ}$ estaba dedicado al sistema de enseñanzas especiales que preparaban para obtener grados académicos y ejercer ciertas profesiones en la sociedad como las medicina y la abogacía. En toda esta parte se regularon las pasantías, las conferencias semanales, la distribución de los cursos y de la enseñanza en cada uno de ellos, las diversas indicaciones sobre el procedimiento de las escuelas, y los deberes de catedráticos y alumnos.

Al tratarlo se presentaron tres cuestiones: el número de cursos que convendría exigir para obtener grados en teología, jurisprudencia y medicina; el número de estos grados; y la habilitación de la enseñanza en establecimientos privados para ofrecerlos. Entre las varias disposiciones sobre la materia, en concejo se ha fijado en el número de 6 cursos que pedía el plan de estudios del año $6^{\circ}$ para obtener grados en dichas facultades mayores, y dos más de práctica antes de entrar a ejercer la profesión de médico o abogado.

Todo el personal de la instrucción pública y de los establecimientos destinados a ella, se comprende en el título quinto. De las personas se pasa en el título sexto a los fondos y rentas de las universidades y colegios; su recaudación, inversión y contabilidad. Respecto de los fondos y rentas aplicados a la instrucción pública, y a sus establecimientos, el Concejo respetó la posesión y la voluntad de los donadores. La aprobación definitiva de las cuentas se dejó a las Cámaras de Provincia porque la localidad del interés y de los fondos las llamaba naturalmente a velar con celo sobre el buen manejo y la debida aplicación de estos.

La sanción general de las disposiciones del código respecto de las funciones de la instrucción pública, y de sus establecimientos, es la materia de su título $7^{\circ}$ que trataba de las faltas que aquellas pueden cometer en el cumplimiento de sus deberes, las penas en que incurrían y el modo de proceder en su aplicación.

Lo concerniente al establecimiento y observancia exclusiva de este código y a la remoción de las dificultades que en su ejecución pudieran presentarse, se encontraba en su título $8^{\circ}$ y final.

Acompañaron al código dos proyectos de decretos que en él se indicaban y que eran indispensables para que pudiera llevarse a afecto. E1 primero dividía el territorio del Estado en distritos universitarios; el segundo fijaba las asignaciones de que habían de gozar los empleados en la dirección general, subdirecciones, e inspecciones provinciales de instrucción pública, y designaba los fondos de donde habían de pagarse, en esta designación, se distribuyó el gasto entre los fondos nacionales y locales en proporción a lo nacional o local de su objeto.

\section{A MANERA DE CONCLUSIÓN}

La educación en Colombia ha tenido desde sus inicios hasta la actualidad una gran preocupación por la calidad y la cobertura a nivel nacional. Es sorprendente como desde los años veinte de 1800, existían organismos que al mejor estilo francés, se preocupaban por lo que hoy denominamos currículo, plan de estudios y metodologías de enseñanza, lo curioso es que aun hoy estos conceptos no están totalmente claros y los cambios son continuos en los programas de educación, razón por la cual es difícil hacer un balance de las medidas que han tenido éxito o no en el desarrollo de la educación colombiana, y ni que decir sobre la pretensión de una formación integral basada en los valores y los principios morales con la ilusión de crear ciudadanía en términos políticos.

Se destaca como desde esta época los aspectos democráticos estaban presentes en las instituciones de enseñanza, como los padres y los alumnos hacían parte de los consejos y organismos directivos de las instituciones, al mejor ejemplo de los manuales de convivencia actuales y de los proyectos educativos institucionales. 
En definitiva, sólo resta decir que el titulo de este escrito tiene su razón de ser en el sentido de que al realizar la investigación descubrí que pocas cosas nuevas le ha aportado la constitucionalización del derecho con la Carta de 1991 al sistema educativo colombiano de los años veinte de 1800, consiente de la autonomía de las regiones, las particularidades de la enseñan$\mathrm{za}$, el reconocimiento de salarios dignos a los maestros, las libertades de cátedra y la autonomía universitaria.

\section{BIBLIOGRAFÍA}

- EL CONSTITUCIONAL. Trimestre I, domingo 16 de octubre de 1831.

- EL CONSTITUCIONAL. Trimestre I, domingo 27 de noviembre de 1831.

- EL CONSTITUCIONAL. Trimestre I, domingo 4 de diciembre de 1831.

- EL CONSTITUCIONAL. Trimestre I, domingo 18 de diciembre de 1831 .

- EL CONSTITUCIONAL. Trimestre 2, domingo 25 de diciembre 1831.

- EL CONSTITUCIONAL. Trimestre 2, domingo 1 de enero de 1832 .

- EL CONSTITUCIONAL. Trimestre 2, domingo 9 de enero de 1832 .

- EL CONSTITUCIONAL. Trimestre 2, domingo 4 de marzo de 1832.

- EL CONSTITUCIONAL. Trimestre 4, domingo 19 de agosto de 1832 .

- EL CONSTITUCIONAL. Trimestre 4, domingo 25 de noviembre de 1832 .

- EL CONSTITUCIONAL. Trimestre 2, domingo 26 de febrero de 1832 .

- EL CONSTITUCIONAL. Trimestre 2, domingo 20 de noviembre de 1831.

- EL CONSTITUCIONAL. Trimestre 2, domingo $1^{\circ}$ de diciembre de 1831 .

- EL CONSTITUCIONAL. Trimestre 2, domingo 2 de enero de 1832 .

- EL CONSTITUCIONAL. Trimestre 3, domingo 8 de enero de 1832 .

- EL CONSTITUCIONAL. Trimestre 1, domingo 18 de diciembre de 1831 .

- EL CONSTITUCIONAL. Trimestre 1, domingo 25 de diciembre de 1831.
- EL CONSTITUCIONAL. Trimestre 2, domingo 15 de diciembre de 1832 .

- EL CONSTITUCIONAL. Trimestre 5, domingo 23 diciembre de 1832.

- EL CONSTITUCIONAL. Trimestre 6, domingo 3 de marzo de 1833.

- EL CONSTITUCIONAL. Trimestre 6, domingo 20 enero 1833.

- EL CONSTITUCIONAL. Trimestre 6 domingo 10 febrero 1833 .

- EL CONSTITUCIONAL. Trimestre 7 domingo 23 junio de 1833.

- EL CONSTITUCIONAL. Trimestre 6 domingo 24 febrero de 1833.

- EL CONSTITUCIONAL. Trimestre 8 domingo 29 febrero de 1833.

- EL CONSTITUCIONAL. Trimestre 7 domingo 28 abril de 1833 .

- EL CONSTITUCIONAL. Trimestre 7 domingo 28 abril 1833.

- EL CONSTITUCIONAL. Trimestre 7 domingo 28 abril 1833.

- EL CONSTITUCIONAL. Trimestre 9 domingo 8 diciembre 1833 .

- EL CONSTITUCIONAL. Trimestre 12 domingo 14 septiembre 1834.

- EL CONSTITUCIONAL. Trimestre 10 domingo 16 marzo 1834.

- EL CONSTITUCIONAL. Trimestre 10 domingo 23 marzo 1834.

- EL CONSTITUCIONAL. Trimestre 10 domingo 30 marzo 1834.

- EL CONSTITUCIONAL. Trimestre 11 domingo 6 abril 1834 .

- EL CONSTITUCIONAL. Trimestre 11 domingo 20 abril 1834.

- EL CONSTITUCIONAL. Trimestre 11 domingo 25 mayo 1834.

- EL CONSTITUCIONAL. Trimestre 11 domingo 1 junio 1834 .

- EL CONSTITUCIONAL. Trimestre 1 domingo 2 marzo 1834.

- EL CONSTITUCIONAL. Trimestre 12 domingo 3 agosto 1834 .

- EL CONSTITUCIONAL. Trimestre 11 domingo 11 mayo 1834.

- EL CONSTITUCIONAL. Trimestre 13 domingo 30 noviembre 1834. 
- EL CONSTITUCIONAL. Trimestre 13 domingo 14 diciembre 1834.

- EL CONSTITUCIONAL. Trimestre 13 domingo 21 de diciembre 1834 .

- EL CONSTITUCIONAL. Trimestre 9 domingo 29 de diciembre 1834 .

- EL CONSTITUCIONAL DE CUNDINAMARCA. Trimestre 14, domingo 4 de enero de 1835.

- EL CONSTITUCIONAL DE CUNDINAMARCA. Trimestre 14, domingo 8 de marzo de 1835.

- EL CONSTITUCIONAL DE CUNDINAMARCA. Trimestre 14, domingo 22 de marzo de 1835.
- El CONSTITUCIONAL DE CUNDINAMARCA. Trimestre 14, domingo 14 de junio de 1835.

- EL CONSTITUCIONAL DE CUNDINAMARCA. Trimestre 17, domingo 6 de octubre de 1835.

- EL CONSTITUCIONAL DE CUNDINAMARCA. Trimestre 14, domingo 11 de ENERO de 1835.

- EL CONSTITUCIONAL DE CUNDINAMARCA. Trimestre 14, domingo 18 de ENERO de 1835.

- EL CONSTITUCIONAL DE CUNDINAMARCA. Trimestre 14, domingo 25 de ENERO de 1835. 